\title{
O ESPAÇO DA LITERATURA ORAL NA HISTORIOGRAFIA LITERÁRIA BRASILEIRA
}

Carolina do Socorro Antunes Santos Universidade Federal de Minas Gerais

Alguma coisa está fora da ordem. Caetano Veloso (adaptado)

\section{1 - Introdução}

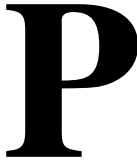

oder-se-ia pensar que a palavra literatura, do latim litteratura, por sua vez originada de littera, letra, identifique somente o campo de manifestações da palavra escrita. A prática da literatura, entretanto, não diz respeito apenas a um conceito etimológico, "sobretudo quando lembramos que nenhum povo deixou de produzir literatura por não ter escrita". ${ }^{1}$ Isso equivale a dizer que a história pode também ser escrita com a evidência acumulada de pessoas vivas, suas criações, ilustrações produtoras de prazer que podem ser ou se tornar especiais para o conhecimento das sociedades modernas e documentadas. Ezra Pound alude a uma série de procedimentos - fanopéia, logopéia e melopéia - que incorporam diversas significações ao signo verbal, mas que não estão, necessariamente, presos ao letramento, pois "na palavra há muito mais que uma referência: há som, sentido, grafismo verbivoco-visual". ${ }^{2}$

${ }^{1}$ MACHADO, Irene A. Oralidade viva e oralidade escrita no texto. In: Language and literature today: procedings of the XIXth Trienmnial Congress of the International Federation for Moderns Languages and Literatures. Brasília: UNB, 1993, p.1146.

${ }^{2}$ POUND, Ezra. Apud MACHADO, Irene A. Op. cit. p.1147. 
Nesse sentido, é bom lembrar que, em todos os tempos e em todos os povos, sempre existiram os relatos orais, que são considerados o fundamento da cultura. Sob o ponto de vista popular, temas e estruturas que se referem à organização do mundo parecem se manter nesses relatos plenos de cotidiano e descontinuidade, autênticos registros de vida. Trata-se, pois, de considerar a literatura, nas suas manifestações populares ou de elite, como o lugar de expressão dos fatos culturais, espaço onde é possível escrever, interpretar, produzir sentido, ou seja, reinventar a história.

Em "Henri Christophe: mito e história", ${ }^{3}$ Maria Nazareth Soares Fonseca mostra-se enfática ao visualizar a literatura como um espaço "privilegiado" para os povos colonizados expressarem o seu inconsciente e manifestarem suas particularidades, ou seja, as formas de produção de sua cultura pelas quais é possível buscar a sua identidade.

No caso do Brasil, cuja historiografia se caracteriza, no que se refere à literatura oral, pela ausência de estudos sobre a produção popular, reflete-se uma situação que não é isolada em relação a outras historiografias literárias. A fragilidade implícita das fontes orais, consideradas universais, reforça a implantação de uma ordem escolhida como modelar, que estimula o processo de descaracterização do outro. E é nesse espaço de descaracterização, entrelugar de faltas e de perdas, espaço de identidade fragmentada, que entra a cultura popular e o sentido de estranhamento que o discurso dessa cultura produz. Cabe, então, aos estudiosos da literatura, da história... desvelar esse espaço para que possam apreender esse discurso que se marca pelas diferenças.

A insersão da literatura oral na historiografia literária brasileira, em que essa continua figurando pela ausência, apesar da relevância de A literatura oral no Brasil, de Luís Câmara Cascudo, seria compreendida, então, como algo que, preenchendo uma lacuna,

${ }^{3}$ FONSECA, Maria Nazareth Soares. Henri Christophe: mito e história. Ensaios de Semiótica, n.14, p.179-192. 
ampliaria o espaço dessa historiografia e possibilitaria a sua transformação num hipertexto, virtualidade sempre pronta a novas alterações, que se fariam, inevitavelmente, a partir de um metaconhecimento inerente às comunidades. No entanto, os estudos históricos e literários continuam atestando persistente existência dessa lacuna, denotadora da preterição dos dados orais e populares em geral na construção da história e que são discriminados pela historiografia literária em termos da construção e do reconhecimento da literatura oral.

\section{2 - A História vista de baixo e a literatura oral: uma luz no fim do túnel?}

Embora date do século XIX o interesse por uma história econômica e social mais ampla, somente durante as duas últimas décadas os historiadores se sentiram atraídos para a exploração de novas perspectivas do passado através de fontes até então despercebidas: memórias, diários, cartas, registros paroquiais, casos judiciais, testamentos etc, advindos das classes não-dominantes, pontos de vista de pessoas comuns como, por exemplo, o do soldado raso e o do operário, "que seriam utilizados para explorar ações e idéias explícitas ou suposições implícitas, e também para propiciar uma base quantitativa às experiências do passado". ${ }^{4}$

Essas perspectivas de exploração do passado possibilitariam aos historiadores - diz Jim Sharpe - ampliar os limites de sua disciplina, abrir novas áreas de pesquisa e, principalmente, explorar experiências de homens e mulheres comuns, ignoradas pela principal corrente da história. Apesar de sedutora, essa perspectiva da escrita dessa nova história apresenta-se dificultosa em termos de evidência e conceituação. Quanto mais longínquo o passado, mais restritas são as fontes. Que história vem de baixo? Da cultura

${ }^{4}$ SHARPE, Jim. A história vista de baixo. In: BURKE, Peter (Org.). A escrita da história. Trad. Magda Lopes. São Paulo: UNESP, 1992. p.48. 
popular? Onde o baixo está situado? Se escrita, o que seria feito com essa "disciplina"? Apesar dessas e outras indagações, vislumbra-se a escrita desse tipo de história como uma alternativa que não só corrigiria a História Oficial como também viria a se constituir numa síntese mais rica da compreensão histórica das comunidades e das pessoas, uma vez que, a partir de um movimento em direção a um âmbito mais amplo das preocupações históricas, haveria uma compreensão mais profunda da sociedade e das pessoas culturalmente diferentes. Além disso, como aponta Jim Sharpe,

(...) a expressão "história vista de baixo" implica que há algo acima para ser relacionado. Esta suposição, por sua vez, presume que a história das "pessoas comuns", mesmo quando estão envolvidos aspectos explicitamente políticos de sua experiência passada, não pode ser dissociada das considerações mais amplas da estrutura social e do poder social. $^{5}$

Mas, apesar da mobilização provocada pelos estudiosos da história nova e das idéias relevantes desses historiadores, a principal corrente da história, ou seja, a história vista de cima, receando talvez a despolitização de sua disciplina e a fragmentação do conhecimento histórico, continua contruindo seus temas a partir das opiniões políticas da elite.

A história e a literatura são unidades independentes, porém completam-se reciprocamente. São discursos, portanto, narrativas que escrevem os/sobre os fatos culturais, que os interpretam e lhes dão sentido, logo, são produtos de uma cultura, documentos que cumprem uma função. Mas, tanto na história quanto na literatura, essa função não alcança a sua completude. Assim como a história vista de baixo parece não se constituir como uma abordagem da história nem como um tipo distinto da mesma, a literatura oral pode ser vista, no Brasil, de modo semelhante, ou seja, ela não está inscrita como uma abordagem nem como um tipo distinto da literatura. Isso mostra, conforme já apontamos, que a literatura oral não foi

${ }^{5}$ SHARPE, Jim. Op. cit. p.54. 
instalada, ou seja, ela não apresenta registro na historiografia literária brasileira.

Por que, na nossa historiografia literária, não há espaço para a literatura oral? Porque essa literatura rompe com os padrões temporais, não respeitando a história dos acontecimentos na sua cronologia? Por não privilegiar os grandes homens e os grandes eventos? Por não possuir uma necessária qualificação literária? Essas perguntas resumem os inúmeros pontos de interrogação e as grandes incertezas que envolvem a questão da falta de inscrição da literatura oral na historiografia literária brasileira. Para essas perguntas, por enquanto, não existem respostas satisfatórias.

As palavras de Eugène Enriquez sintetizam, eu penso, a grande proposta dos estudiosos da literatura oral:

pensar a literatura como um sistema articulado com os demais tipos de representação elaborados pela sociedade para construir, no espaço do imaginário, os meios de sua proteção e a garantia da transmissão de seus valores. ${ }^{6}$

Uma proposta revolucionária, com certeza, que conduz à reflexão dos diversos aspectos das relações culturais e das formas que viabilizam essas relações no texto de literatura. Esse texto, como a obra de arte e a cultura em geral, seria visto como um espaço de encontros e diálogos, nos quais as imagens construídas sobre o outro mostrar-se-iam sensíveis às diferenças e buscariam a interação. A inter-relação cultural seria, então, vista como ganho e não como ameaça. Uma literatura assim concebida, polifonicamente, interage com a concepção de imaginário social, conjunto de representações sociais que conferem identidade à sociedade. Esse imaginário, então, é visto como sistema simbólico através dos quais as sociedades se percebem em termos de suas diferenças e de seus poderes. Essa

${ }^{6}$ ENRIQUEZ, Eugène. Imaginário social, recalcamento e repressão nas organizações, apud FONSECA, Maria Nazareth Soares. Literatura e imaginário social. In: Literatura e diferença. IV Congresso ABRALIC. São Paulo, 1995. p.445. 
percepção do imaginário está certamente ligada às propostas da história nova, segundo a qual,

numa sociedade, qualquer que seja, tudo se liga e se comanda mutuamente: a estrutura política e social, a economia, as crenças, as manifestações mais elementares e mais sutis da sociedade.?

Essas palavras de Le Goff sugerem uma nova composição do texto histórico, cujo tecido narrativo seria constituído de vozes diversas e em que, na ação ou nas ações narradas, as representações de uma sociedade e de uma época formariam um sistema articulado com outros sistemas, tais como a religião, os modos de comunicação etc.

Ratifica-se, pois, que o imaginário, em todo o seu contexto mental, cultural e social, constitui-se em objeto tanto da história quanto da literatura, uma vez que, nessas duas disciplinas, ele é um solo fértil a ser explorado. Necessário se faz, por isso, viabilizar o estudo e a discussão de todas essas questões, em especial as que se referem à oralidade, para que, nas fontes do imaginário, sejam encontrados enriquecimentos e continuidades.

Afirma Adolfo Colombres:

La entusista aceptación de las ventajas de la escritura impidió vislumbrar siquiera hasta épocas recientes sus aspectos negativos, y produjo una desvalorización apresurada y acrítica de la oralidad, cuyas sutilezas técnicas siguen en gran medida inexploradas... ${ }^{8}$

Conforme esse autor, a oralidade tem sido sempre o sustento dos mitos, o fundamento da cultura, e o relato oral, por sua vez, constitui-se no padrão verdadeiramente universal, e isso não poderia ser dito do relato escrito. Colombres refere-se, na literatura elitista,

7 LE GOFF, Jacques. A história nova. In: A bistória nova. Trad. Eduardo Brandão. São Paulo: Martins Fontes, 1983. p.32.

8 COLOMBRES, Adolfo. Palavra y artificio: las literaturas "barbaras". In: PIZARRO, Ana (Org.). América latina: palavra, literatura e cultura. vol. 3. Campinas: Ed. da UNICAMP, 1994. p.138. 
ao distanciamento desse relato de sua base tradicional, na qual o passado é uma força espiritual, uma palavra que anima, ilumina e transforma, portanto, merece ser cultivado.

Na literatura oral, esse passado, como uma via de mão dupla, está sempre presente. Por isso, talvez, nela se concentre a maior força expressiva da cultura popular. A literatura oral, que deve assim se apropriar do passado, recompondo-o e tornando-o presente, pode ser pensada como um grande texto, que implica textos múltiplos e vários públicos. Ela nos apresenta um espaço desconhecido, feito de miudezas e pequenas personagens, feito de pequenas trocas simbólicas, que não se configura como o dos grande fatos históricos, mas igualmente um espaço pleno para a produção de um texto rico por suas características, valores, atitudes e uma maneira de interpretar o mundo peculiarmente nacionais. Esse texto é constituído de várias vozes, pois o repertório manipulado é de todos. Por trás do discurso do narrador, subjazem outros discursos: de personagens, de épocas, de outros autores, de outras épocas. Assim, "uma [voz] não se sobrepõe à outra, mas todas mantêm a plenivalência do que anunciam”. 9 Não se justifica, portanto, a postura classista e autoritária que encara a presença da poesia popular no mercado cultural institucionalizado e na comunicação como algo que prejudica a sua representatividade e dignidade.

Constata-se que a literatura oral, se estudada convenientemente pelos teóricos da literatura, pode ganhar voz na narrativa. Assim, ela poderá ter uma presentificação corporal na historiografia literária brasileira, que deverá incorporar, nas suas antologias, a literatura de cordel no Nordeste e, quem sabe, os contos fantásticos do Vale do Jequitinhonha.

${ }^{9}$ MACHADO, Irene A. Op. cit. p.1148. 


\section{3 - Conclusão}

De acordo com uma corrente mais tradicional de estudiosos da literatura oral, não só as grandes mudanças nos sistemas de produção, com as suas conseqüentes transformações - nas relações de vizinhança, nas formas de moradia, no emprego do tempo no trabalho e no lazer etc -, como também os meios de comunicação de massa colaboram para o enfraquecimento da literatura popular tradicional, que apenas sobrevive, há muito tempo, como espécie ameaçada de extinção. Sobre esses últimos afirma, enfaticamente, Maria José Londres:

Os meios de comunicação de massa fazem no Brasil o que fazem em toda parte: anulam as fronteiras regionais, submetem as produções nacionais às estrangeiras e tudo é conformado em feitio industrial moderno (que tem como primeiro e máximo objetivo o lucro), muito distante da alma das culturas velhas até de milênios. ${ }^{10}$

Entretanto, no sentido de relativizar essas palavras, cabe lembrar que a história da literatura oral poderá apresentar um novo rumo, pois "uma luz existe no fim do túnel".

Sabe-se que, na situação de opressão, por menor que ela seja, forma-se também a liberação, que tende a se alastrar a partir das tensões advindas das desigualdades sociais, principais fontes de inovação e ruptura. A teoria literária tem se constituído, nas últimas décadas, em fonte instigante de discussão de métodos que podem levar a reinterpretações do mundo, a confrontos de pontos de vista que conduzem, necessariamente, a uma visão mais abrangente e mais profunda do aparato teórico e dos fatos literários.

Em se tratando da relação literatura oficial/literatura oral, hoje é possível (re)afirmar que não existe o anticânone. A idéia de

${ }^{10}$ LONDRES, Maria José. Literatura popular. In: PIZARRO, Ana (Org.). América latina: palavra, literatura e cultura. vol. 2. Campinas: Ed. da UNICAMP, 1994. p.423. 
fronteira instalada nessa relação contém em si a marca de interseção, de busca de dissenso que propicia, no embate com o outro (ou outra!), marcar-se a diferença. Nesse embate, a literatura oral tende a ganhar mais espaço a partir de um aparelho teórico no mínimo respeitável. Sejam citados o método comparatista, "que propõe a análise dos textos em processo de reinserção em suas culturas específicas porque nelas ganham expressão" ${ }^{11}$, o universo conceitual de Paul Zumthor e as formulações bakhtinianas que "só podem ser devidamente avaliadas no contexto das pesquisas sobre a oralidade". ${ }^{12}$ A poética da oralidade de Paul Zumthor e a teoria do dialogismo de Bakhtin ampliam e enriquecem o aparato teórico da literatura, reanimam "a paixão pela palavra viva inscrita ou escrita no texto..."13 e desenvolvem a necessidade de se criar uma ciência literária na qual sejam incluídas a oralidade e as literaturas populares. Assim, no caso do Brasil, poderá ser dado um impulso rumo a uma historiografia literária mais completa, em que a literatura oral e a literatura oficial se iluminem reciprocamente.

${ }^{11}$ BENIATTI, Ilva. Literatura e história: a elaboração ficcional do fato histórico. In: Language and literature today: procedings of the XIXth Congress of the International Federation for Moderns Languages and Literatures. Brasília: UNB, 1994. p.1184.

${ }^{12}$ MACHADO, Irene A. Op. cit., p.1146.

${ }^{13}$ MACHADO, Irene A. Op. cit., p.1147. 


\section{Referências Bibliográficas}

BONIATTI, Ilva. Literatura e história: a elaboração ficcional do fato histórico. In: Language and literature today: proceedings of the XIXth Congress of the International Federation for Moderns Languages and Literatures. Brasília: UNB, 1996, p.1174-1185.

COLOMBRES, Adolfo. Palabra y artificio: las literaturas barbaras. In: PIZARRO, Ana (Org.). América Latina: palavra, literatura e cultura. Vol. 3. Campinas: Ed. da UNICAMP, 1994. p.127-167.

FONSECA, Maria Nazareth Soares. Henri Christophe: mito e História. Ensaios de Semiótica, Belo Horizonte, v.14, p.179-192, dez. 1985.

FONSECA, Maria Nazareth Soares. Literatura e imaginário social. In: Literatura e diferença. IV Congresso ABRALIC. São Paulo, 1995. p.445-456.

LE GOFF, Jacques. A história nova. In: A história nova. Trad. Eduardo Brandão. São Paulo: Martins Fontes, 1983, p.25-64.

LONDRES, Maria José. Literatura popular. In: PIZARRO, Ana (Org.). América Latina: palavra, literatura e cultura. Vol. 3. Campinas: Ed. da UNICAMP, 1994. p.407-423.

MACHADO, Irene A. Oralidade viva e oralidade escrita no texto. In: Language and literature today: proceedings of the XIXth Congress of the International Federation for Moderns Languages and Literatures. Brasília: UNB, 1996. p.1146-1149.

RIO, João do. Pequenas profissões. In: A alma encantadora das ruas. Rio de Janeiro: Organizações Simões, 1951. p.41.

SHARPE, Jim. A história vista de baixo. In: BURKE, Peter (Org.). $A$ escrita da história: novas perspectivas. Trad. Magda Lopes. São Paulo: Ed. UNESP, 1991. p.39-62. 


\section{Resumo}

Neste artigo, faz-se uma breve reflexão sobre o lugar ocupado pela literatura oral na historiografia literária brasileira. Nesse sentido, os estudos dessa modalidade de literatura são associados aos da corrente não-oficial da história, a partir dos quais se vislumbra a possibilidade de inclusão da literatura oral nessa historiografia literária.

\section{Résumé}

Dans cette article, on fait une brève réflexion à propos du lieu occupé par la littérature orale dans l'historiographie littéraire brésilienne. Dans ce sens là, les études de cette modalité de littérature sont associés à celles du courant nonofficiel de l'histoire à partir desquelles on peut entrevoir la possibilité de l'inclusion de la littérature orale dans cette historiographie littéraire. 